\title{
Clinical hyperthermia of prostate cancer using magnetic nanoparticles: Presentation of a new interstitial technique
}

\author{
M. JOHANNSEN ${ }^{1}$, U. GNEVECKOW ${ }^{2,3}$, L. ECKELT ${ }^{2}$, A. FEUSSNER ${ }^{2}$, \\ N. WALDÖFNER ${ }^{3}$, R. SCHOLZ ${ }^{3}$, S. DEGER ${ }^{1}$, P. WUST ${ }^{2}$, S.A. LOENING ${ }^{1}$, \\ \& A. JORDAN ${ }^{2,3}$
}

${ }^{1}$ Department of Urology, Campus Mitte, ${ }^{2}$ Department of Radiology, Campus Virchow-Klinikum, Charité University Medicine Berlin, Germany, and ${ }^{3}$ Center of Biomedical Nanotechnology (CBN), clo Department of Radiology, Campus Virchow-Klinikum, Charité University Medicine Berlin, Germany

(Received 17 February 2005; accepted 26 April 2005)

\begin{abstract}
The aim of this pilot study was to evaluate whether the technique of magnetic fluid hyperthermia can be used for minimally invasive treatment of prostate cancer. This paper presents the first clinical application of interstitial hyperthermia using magnetic nanoparticles in locally recurrent prostate cancer. Treatment planning was carried out using computerized tomography (CT) of the prostate. Based on the individual anatomy of the prostate and the estimated specific absorption rate (SAR) of magnetic fluids in prostatic tissue, the number and position of magnetic fluid depots required for sufficient heat deposition was calculated while rectum and urethra were spared. Nanoparticle suspensions were injected transperineally into the prostate under transrectal ultrasound and flouroscopy guidance. Treatments were delivered in the first magnetic field applicator for use in humans, using an alternating current magnetic field with a frequency of $100 \mathrm{kHz}$ and variable field strength $\left(0-18 \mathrm{kA} \mathrm{m}^{-1}\right)$. Invasive thermometry of the prostate was carried out in the first and last of six weekly hyperthermia sessions of 60 min duration. CT-scans of the prostate were repeated following the first and last hyperthermia treatment to document magnetic nanoparticle distribution and the position of the thermometry probes in the prostate. Nanoparticles were retained in the prostate during the treatment interval of 6 weeks. Using appropriate software (AMIRA), a non-invasive estimation of temperature values in the prostate, based on intra-tumoural distribution of magnetic nanoparticles, can be performed and correlated with invasively measured intra-prostatic temperatures. Using a specially designed cooling device, treatment was well tolerated without anaesthesia. In the first patient treated, maximum and minimum intraprostatic temperatures measured at a field strength of $4.0-5.0 \mathrm{kA} \mathrm{m}^{-1}$ were $48.5^{\circ} \mathrm{C}$ and $40.0^{\circ} \mathrm{C}$ during the 1 st treatment and $42.5^{\circ} \mathrm{C}$ and $39.4^{\circ} \mathrm{C}$ during the 6th treatment, respectively. These first clinical experiences prompted us to initiate a phase I study to evaluate feasibility, toxicity and quality of life during hyperthermia using magnetic nanoparticles in patients with biopsy-proven local recurrence of prostate cancer following radiotherapy with curative intent. To the authors' knowledge, this
\end{abstract}

Correspondence: Dr Manfred Johannsen, Department of Urology, Charité-Campus Mitte, Schumannstr. 20/21, 10117 Berlin, Germany. Tel: 0049-30-450515052. Fax: 0049-30-450515915. E-mail: manfred.johannsen@charite.de 
is the first report on clinical application of interstitial hyperthermia using magnetic nanoparticles in the treatment of human cancer.

Keywords: Prostate carcinoma, interstitial hyperthermia, magnetic nanoparticles

\section{Introduction}

The concept of magnetically mediated heating of iron-oxide nanoparticles is gaining increasing attention as a potential new cancer treatment. In this technique, which has also been termed magnetic fluid hyperthermia $(\mathrm{MFH})$, biocompatible superparamagnetic nanoparticles are injected into the target region and selectively heated by an externally applied AC magnetic field. Carcinoma of the prostate represents an attractive target for minimally invasive, interstitial treatments such as low-dose or high-dose rate brachytherapy and hyperthermia. Both brachytherapy and regional hyperthermia techniques, including magnetically mediated thermoseed hyperthermia, have been evaluated at the Charité clinic during the last 12 years [1-3]. Magnetically mediated hyperthermia using coated nanoparticles may offer several advantages over conventional regional hyperthermia techniques and also magnetic hyperthermia using alloy seeds. While it may be assumed that a more homogeneous intra-tumoural distribution can be obtained with nanoparticles compared to larger seeds, most importantly a higher SAR of these particles has been demonstrated [4, 5]. Moreover, a characteristic of magnetic fluid hyperthermia or thermoablation is the selectivity of treatment, since boundaries of different conductive tissues do not interfere with power absorption, in contrast to E-field dominant systems used in regional hyperthermia. To explore the potential of hyperthermia using magnetic nanoparticles in prostate carcinoma, this technique was recently evaluated in the orthotopic Dunning tumour model of the rat. Thermoablative temperatures of $50^{\circ} \mathrm{C}$ were achieved at a field strength of $15 \mathrm{kA} \mathrm{m}^{-1}$ in the first feasibility study using a less concentrated magnetic

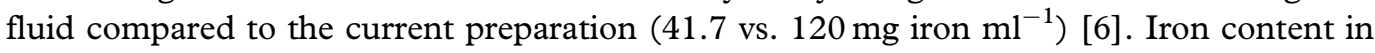
the prostate 13 days after application of magnetic fluid into the prostate was $64 \%$ of the injected amount. In a further in vivo analysis using a nanoparticle preparation comparable to the one used in the current study, intra-prostatic temperatures of $70^{\circ} \mathrm{C}$ could be achieved when the maximum available magnetic field strength of $18 \mathrm{kA} \mathrm{m}^{-1}$ was applied [7]. At a constant field strength of $12.6 \mathrm{kA} \mathrm{m}^{-1}$, mean maximum temperatures of $54.8^{\circ} \mathrm{C}$ (averaged over 12 animals) were obtained following injection of magnetic fluid (up to $0.5 \mathrm{ml} \mathrm{cm}^{-3}$ tumour volume) into the rat prostates. A significant inhibition of prostate cancer growth was demonstrated in this study. Moreover, $82.5 \%$ of the injected amount of iron was retained in the prostates 10 days after intra-tumoural application, allowing for sequential thermal therapies without repeated injection of nanoparticles. These results encouraged our group to evaluate $\mathrm{MFH}$ in patients with localized prostate carcinoma.

\section{Materials and methods}

The nanoparticles used in this study had an average particle core size of $15 \mathrm{~nm}$ and were coated with an aminosilan-type shell in water (MagForce ${ }^{\circledR}$ MFL AS, MagForce ${ }^{\circledR}$ Nanotechnologies $\mathrm{GmbH}$, Berlin, Germany). Concentration of ferrites in aqueous solution was $120 \mathrm{mg} \mathrm{ml}^{-1}$. Treatments were delivered in the first magnetic field applicator for use in humans (MFH300F, MagForce ${ }^{\circledR}$ Nanotechnologies $\mathrm{GmbH}$, Berlin), using an alternating magnetic field with a frequency of $100 \mathrm{kHz}$ and a variable field strength $\left(0-18 \mathrm{kA} \mathrm{m}^{-1}\right)$. This applicator meets the safety and practicability criteria for medical use 
imposed by the respective German authority and has been described recently [8]. Due to its universal design, it can be used for hyperthermia and thermoablation treatment of malignancies in any location of the human body.

A 67 year-old patient with biopsy-proven local tumour progression following high-dose rate brachytherapy $(2 \times 15$ Gy boost to the prostate using Iridium $192,5 \times 1.8$ Gy up to $50.4 \mathrm{~Gy}$ external radiation to the prostate and pelvis) for clinical T3 prostate carcinoma 4 years earlier, who did not tolerate hormonal therapy, was subjected to staging to exclude metastases (bone scan, magnetic resonance imaging) and signed an informed consent form. Treatment planning was based on thin-sliced $(2.5 \mathrm{~mm})$ computerized tomography (CT) of the prostate, the known SAR of magnetic nanoparticles and the estimated perfusion and distribution of particles in prostatic tissue. From the results in the rat model of prostate cancer and preliminary experience in human tumours such as cerebral glioblastoma and recurrent soft tissue sarcomas (manuscripts in preparation), it was assumed that, for sufficient heating of the human prostate gland, at an alternating current magnetic field strength of $10 \mathrm{kA} \mathrm{m}^{-1}, 0.2 \mathrm{ml}$ of magnetic fluids per $\mathrm{ml}$ tumour volume would be necessary to reach an SAR of $300 \mathrm{~W} \mathrm{~kg}^{-1}$, assuming homogeneous nanoparticle distribution. This would imply that for a normal prostate volume of $20 \mathrm{ml}$, assuming no loss of magnetites into the blood stream or outside the prostate, $4 \mathrm{ml}$ of undiluted magnetic fluid had to be injected. With the same amount of injectate, but a prostate volume of $40 \mathrm{ml}$, $\sim 150 \mathrm{~W} \mathrm{~kg}^{-1}$ could be reached [8]. Using the AMIRA-software, together with a newly developed prostate module, 3-dimensional CT reconstruction images of the prostate were obtained and number and position of magnetic fluid depots required for sufficient heat deposition in the prostate were calculated [9]. A minimum distance of $0.5 \mathrm{~cm}$ between the virtual nanoparticle depots and the margin of rectum or urethra was appointed in the plans. The patient was placed in lithotomy position and transrectal ultrasound (TRUS) images of the prostate were obtained $(0.5 \mathrm{~cm}$ slices, B\&K medical ultrasound scanner, classic 1 type $\mathrm{B}, 7.5 \mathrm{mHz}$ ). A transurethral catheter was placed and the balloon was blocked with $50 \%$ solution of contrast medium and water for better visualization of the position of bladder neck and base of the prostate. With the transrectal ultrasound device being visible on flouroscopy, the craniocaudal extension of the prostate as seen on TRUS images was marked in $0.5 \mathrm{~cm}$ steps on the flouroscopy screen with a marker pen. Ultrasound images were correlated with the CT pre-planning data and adjusted on-site for small variations that may be caused by different bowel position/content or bladder filling. Using a templet and a $18 \mathrm{G}$ needle, the nanoparticle suspension was injected transperineally into the prostate under sterile conditions, general anaesthesia and TRUS/ flouroscopy guidance (Figure 1). Precisely, the desired position of the needle was found using cross-sectional view in TRUS, whereas the correct longitudinal position was controlled by TRUS and flouroscopy. During injection of magnetic fluid, a distance of $\sim 1 \mathrm{~cm}$ from the position of the application needle, representing the presumed centre of the nanoparticle depot, to the rectum and the urethra was maintained. In the first patient, at a prostate size of $35 \mathrm{ml}$, a total of $12.5 \mathrm{ml}$ of magnetic fluid were injected as 24 depots covering the prostate. Four closed-end catheters were placed in the prostate for thermometry and fixed with sutures at the perineum. The patient was placed in the AC magnetic field applicator and fibre-optic thermometry probes (Luxtron Corp. Santa Ana, CA, USA, diameter $0.55 \mathrm{~mm}$ accuracy: $\pm 0.3^{\circ} \mathrm{C}$ ) were positioned in the prostate, urethra, rectum, perineum, scrotum and left ear. A cooling device was positioned in both groins and the perineum and connected to a water pump. The treatment set-up is illustrated in Figure 2. The urethral catheter was closed with a clamp during treatment. With the patient fully awake, thermotherapy was started at a magnetic field strength of $2.5 \mathrm{kA} \mathrm{m}^{-1}$. 


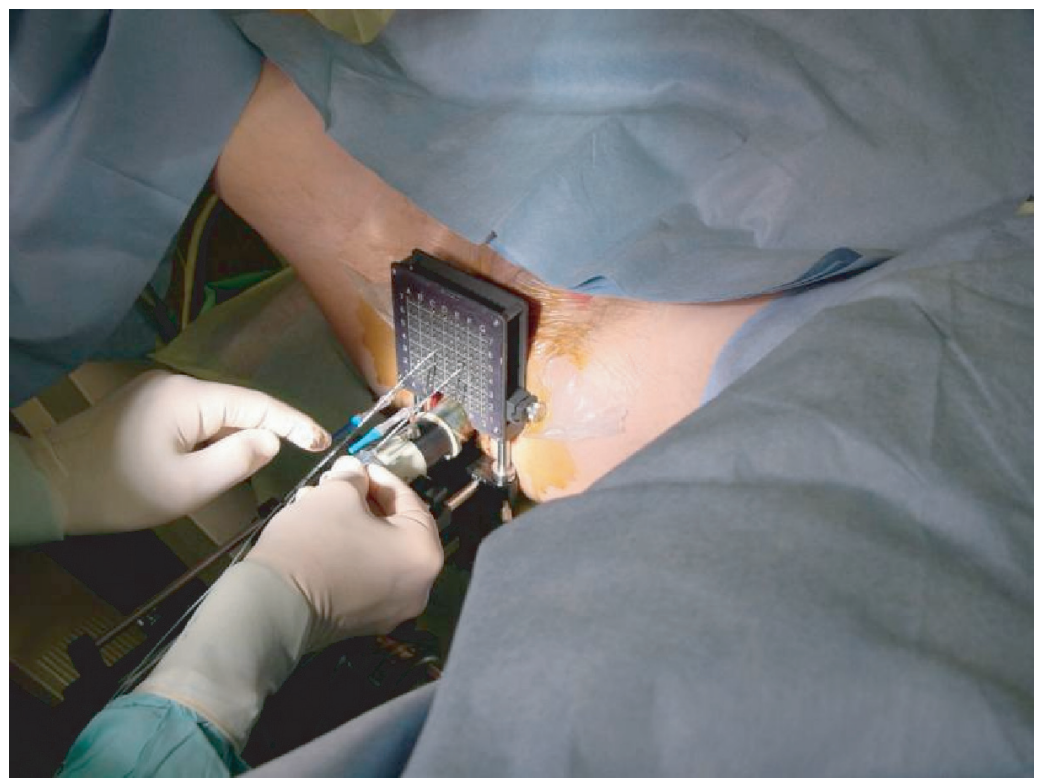

Figure 1. Application of nanoparticle suspension into the prostate is carried out transperineally with the patient in lithotomy position. The procedure is performed under transrectal ultrasound and flouroscopy guidance. At the centre, the templet used for magnetic fluid injection as well as implantation of closed-end catheters to house the thermometry probes can be appreciated.

The time-temperature course was monitored online with thermotherapy application software (MagForce ${ }^{\circledR}$ Nanotechnologies $\mathrm{GmbH}$ ), so that the AC magnetic field strength could be kept constant or be manually adjusted to the desired steady-state temperature in the tumour. At a low field strength, temperature mapping was carried out in the prostate, urethra and rectum to document the position with the highest temperature at which the probes were subsequently left. Magnetic field strength was gradually increased to $5.0 \mathrm{kA} \mathrm{m}^{-1}$ and kept constant for $60 \mathrm{~min}$. Five subsequent hyperthermia treatment sessions took place at weekly intervals. Before the sixth treatment, four thermometry probes were placed (two in the right and two in the left lobe of the prostate). Immediately after the first and last hyperthermia treatment, CT-scans of the prostate were performed. In the CT images, magnetic nanoparticle depots in the prostate could be visualized as regions with higher density compared to the surrounding tissue, expressed as Hounsfield units (Figure 3). At a density $\left(\mathrm{g} \mathrm{ml}^{-1}\right.$ iron) of above $10 \mathrm{gl}^{-1}$ iron, which corresponds to a dilution of more than 10:1 of the original magnetic nanoparticle suspension, these depots can be well recognized [8]. The temperature distribution can be estimated by scaling the maximum temperatures calculated with the AMIRA-software to the measurements in the reference points of the implanted thermometry catheters. The scaling factor is represented by the SAR in the area containing the nanoparticles. Alternatively, the SAR can be determined by measuring the volume of regions with visible nanoparticles, assuming an homogenous particle distribution, on the basis of the known relationship between the $\mathrm{SAR}_{\mathrm{fe}}$ (iron normalized SAR) and the magnetic field $H$. This relationship depends on the concentration of the magnetic fluid used and is influenced by certain properties related to synthesis of nanoparticle suspensions [8]. 


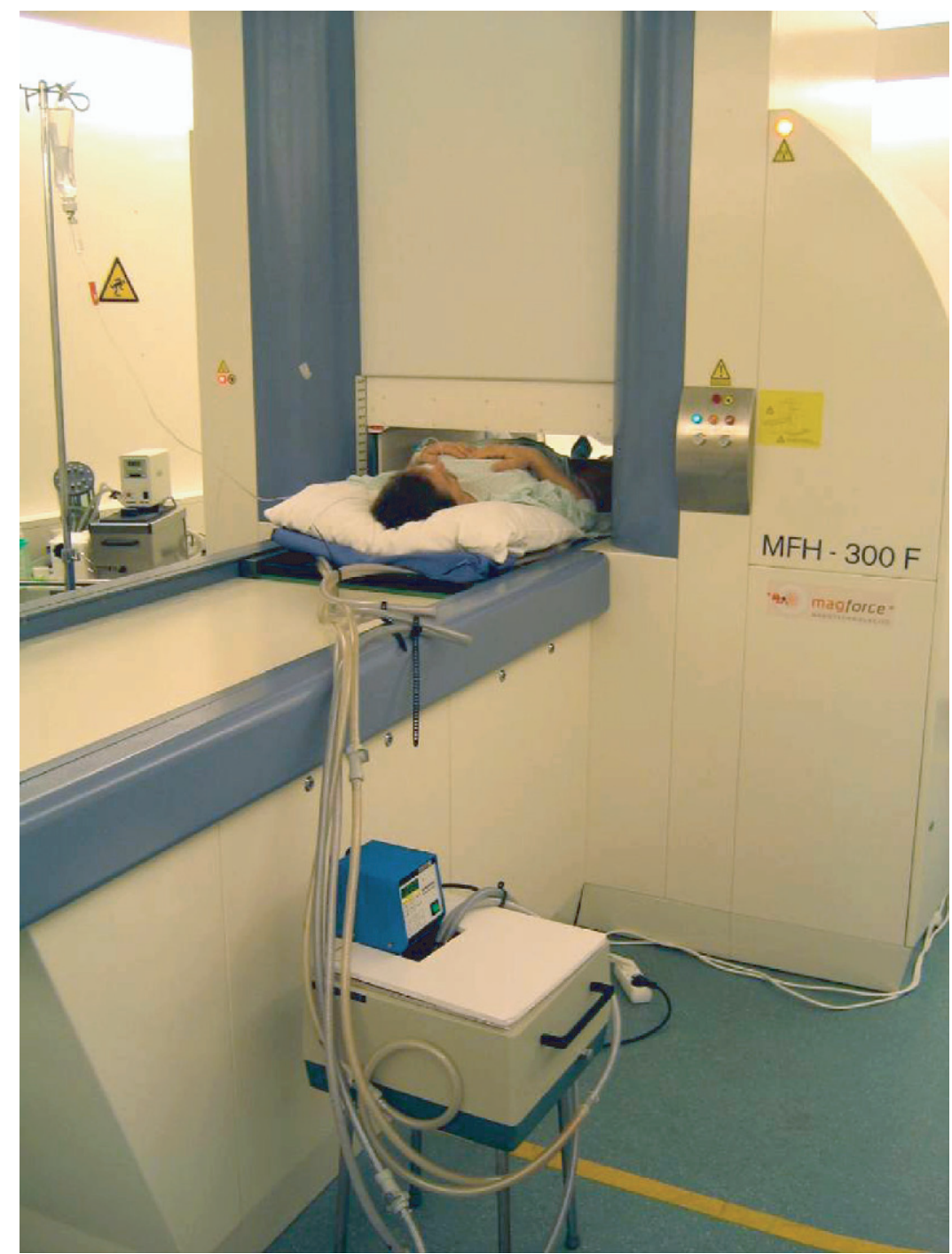

Figure 2. AC magnetic field applicator (MFH300F, MagForce ${ }^{\circledR}$ Nanotechnologies GmbH, Berlin). For cooling purposes, a closed loop of tubes with circulating cold water, which is connected to a water pump, is placed around the patients inner thigh, perineum and the groin on both sides. An alternating magnetic field with a frequency of $100 \mathrm{kHz}$ and variable field strength $\left(0-18 \mathrm{kA} \mathrm{m}^{-1}\right)$ is used. Fibreoptic thermometry probes are positioned in the prostate, urethra, rectum, perineum, scrotum and left ear. Thermotherapy is monitored online with thermotherapy application software, so that the AC magnetic field strength can be kept constant or be manually adjusted to the desired steady-state temperature in the tumour.

\section{Results}

\section{Feasibility and toxicity}

During intra-prostatic application of magnetic fluid, a total of 24 depots of $0.5 \mathrm{ml}$ each were injected into the prostate. The positioning of the depots was executed as intended according to the treatment planning. Nevertheless, application of magnetic fluid proved slightly 

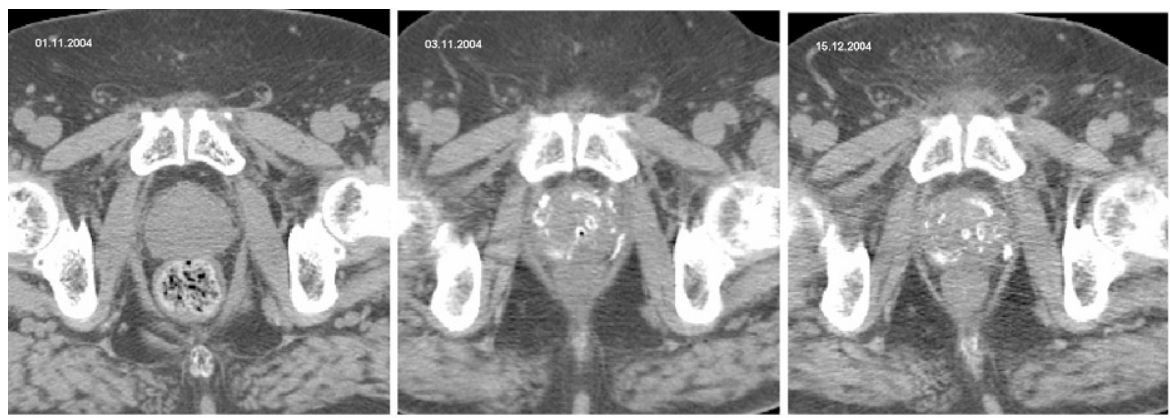

Figure 3. Computerized tomography scans of the prostate performed before (left image), immediately after intra-prostatic injection of magnetic fluid (centre image) and 6 weeks later, after the last hyperthermia treatment (right image). There was no repeated application of nanoparticle suspension in the meantime. The images show iron-oxide nanoparticle depots in the prostate as regions with higher density compared to the surrounding prostate tissue (centre of images). Homogeneous particle distribution was hampered by marked fibrotic changes of the prostate gland induced by previous interstitial irradiation in this case. These images document stable intra-tumoural deposition of nanoparticles in the prostatic tissue for a time frame of at least 6 weeks, which allows for serial thermotherapy treatments without the need for repeated magnetite injections.

difficult because of fibrotic changes of the prostate gland induced by previous brachytherapy. Therefore, injection was done very slowly. During hyperthermia, magnetic field strength was not increased beyond $5.0 \mathrm{kA} \mathrm{m}^{-1}$, because the patient reported increasing discomfort in the perineum. Several times, the patient experienced pain in the groin due to sub-optimal positioning of the cooling device and field strength was temporarily reduced. As a whole, magnetic field strength was kept fairly constant for $\sim 60 \mathrm{~min}$ at $4.0 \mathrm{kA} \mathrm{m}^{-1}$. Figure 4 illustrates the course of a temperature curve obtained from one of the intra-prostatic thermometry probes during treatment, together with the corresponding AC magnetic field strength. Minor pain in the perineal region was treated with analgesics. Otherwise, treatment was well tolerated. The in-dwelling catheter was removed the day after hyperthermia treatments and spontaneous micturition was possible with no residual urine in the bladder. Moderate bladder spasms occurred following magnetic fluid application and the first hyperthermia treatment, which subsided under anti-spasmodic medication.

\section{Intra-tumoural temperatures}

Temperatures in the prostate, urethra and rectum are expressed as maximal and minimal values measured invasively (prostate) or intra-luminally (urethra, rectum) during the actual hyperthermia treatment at a constant AC magnetic field strength of $4.0-5.0 \mathrm{kA} \mathrm{m}^{-1}$. During the first treatment, maximum intra-prostatic temperatures measured by four thermometry probes were $48.5,43.0,43.7$ and $43.6^{\circ} \mathrm{C}$, whereas minimal temperatures were $41.2,40.3$, 40.0 and $41.1^{\circ} \mathrm{C}$, respectively. During the sixth and last treatment, maximum intra-prostatic temperatures were $42.5,42.3,41.5$ and $40.7^{\circ} \mathrm{C}$, whereas minimal temperatures were 40.5 , 39.8, 39.7 and $39.4^{\circ} \mathrm{C}$, respectively. Maximum and minimal temperatures measured in the urethra were 42.4 and $38.0^{\circ} \mathrm{C}$, whereas in the rectum 42.1 and $37.9^{\circ} \mathrm{C}$, respectively, were recorded. 


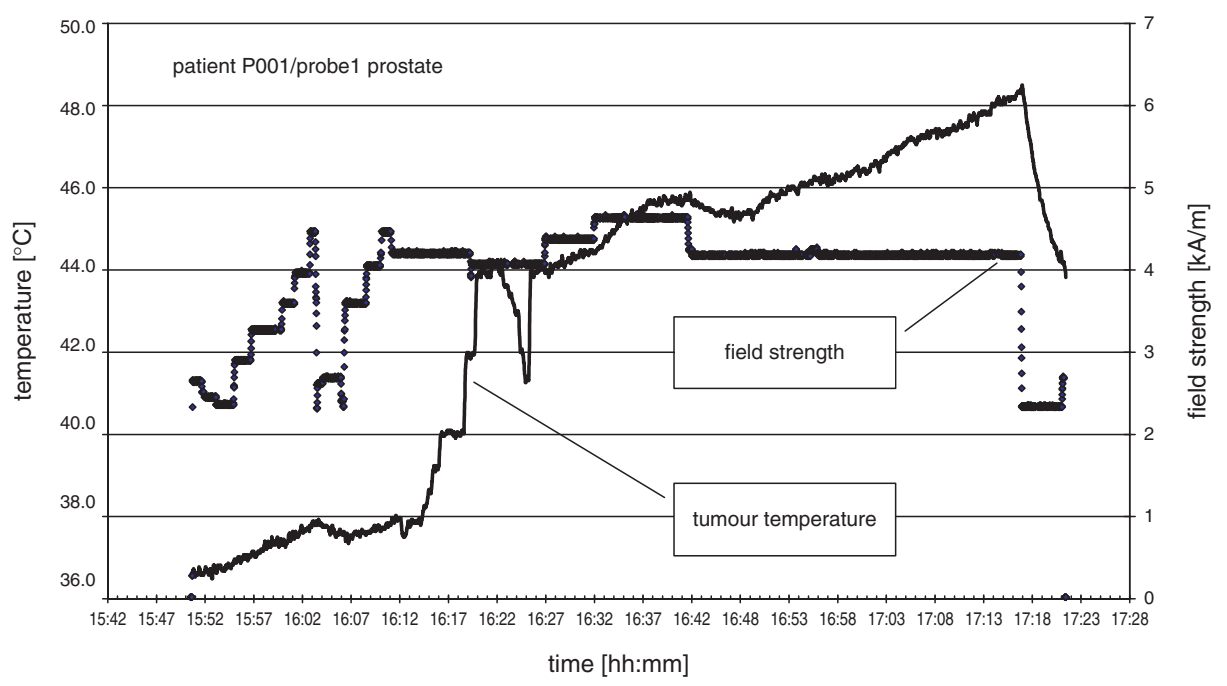

Figure 4. The course of a temperature curve obtained from one of the intra-prostatic thermometry probes during treatment is illustrated together with the corresponding AC magnetic field strength. When the magnetic field strength reached $4.0 \mathrm{kA} \mathrm{m}^{-1}$, the thermometry probe was pulled backwards in $0.5 \mathrm{~cm}$ steps, beginning at the base of the prostate, to document the position with the highest intratumoural temperature, at which the thermometry probe was subsequently left. The downward spike of the temperature curve marks the outer (apical) border of the prostate. Although magnetic field strength was kept fairly constant, intra-prostatic temperature continued to rise until the end of treatment. This indicates that, during the course of treatment, progressively less convection of heat takes place because of warming of the whole targeted volume, possibly also because of collapse of blood vessels due to thermoablative temperatures.

\section{Interstitial deposition of nanoparticles}

Nanoparticle depots in the prostate were still clearly visible on CT 6 weeks after magnetic fluid injection into the prostate (Figure 3). Along with the invasive thermometry data obtained during the last hyperthermia treatment, this documents that nanoparticles are retained in the tumour tissue for at least several weeks and not removed by macrophages. This time interval allows for a sufficient number of heat treatments and represents an important pre-requisite for clinical application of this technique in prostate cancer.

\section{Treatment planning}

During the treatment of the first patient, it was realized that some of the assumptions on which the pre-treatment planning was based had to be altered. This regarded the amount of magnetic fluid to be injected into the prostate and the AC magnetic field strength during therapy. It was found that more magnetic fluid than anticipated was required to infiltrate the prostate and achieve a sufficient heat dose during treatment. This was partly related to the adverse tissue characteristics of pre-irradiated patients, which hampered an optimal distribution of magnetic nanoparticles in the target region. Moreover, when the field strength was increased above $5 \mathrm{kA} \mathrm{m}^{-1}$, the patient experienced discomfort and pain which was difficult to localize exactly, but was referred in the perineum. As a consequence, approximately half of the AC magnetic field strength on which SAR calculations were based 
was actually applied and sustained under clinical conditions. Based on CT images of the first patient treated, the AMIRA software calculated a nanoparticle volume of $14.9 \mathrm{ml}$ within the prostate tissue (sum of the volumes of each nanoparticle depot visualized in the CT images). Assuming an homogeneous distribution of nanoparticles in this area, the estimated SAR within this area was $288 \mathrm{~W} \mathrm{Kg}^{-1}$. Since distribution of particles in the whole prostate gland was not homogeneous, as documented in the CT scans (Figure 3), the SAR in the whole targeted volume cannot reliably be estimated.

\section{Discussion}

Despite much progress in the development of hyperthermia application and treatment planning systems, clinical hyperthermia of prostate cancer is still a challenging problem due to both the position in the pelvis and the high perfusion of this organ. Several techniques have been used for regional hyperthermia of prostate cancer, including radiofrequency, microwave or ultrasound applicators [10-16]. Intra-tumoural temperatures obtained with these methods have mostly been between $40-41^{\circ} \mathrm{C}$. In only a few of these studies, maximum intra-prostatic temperatures of $42.5^{\circ} \mathrm{C}$ were reached or the critical temperature of $43.0^{\circ} \mathrm{C}$, where a measurable cytotoxic effect is documented for various cell lines, was exceeded $[11,14]$. Most of the studies related to the treatment of prostate cancer, however, evaluated hyperthermia in the context of combined thermoradiotherapy, where temperatures in this range are thought to be sufficient for radiosensitization. In fact, the results of several studies evaluating thermoradiotherapy of locally advanced or androgen-independent prostate cancer are certainly better than would be expected if only irradiation had been administered, although evidence to prove this in the form of phase III studies is not available. Invasive and non-invasive thermometry during regional hyperthermia of the prostate has been investigated in some detail $[17,18]$. It was found that temperature distribution in the prostate is heterogeneous and intra-luminal measurements tend to over-estimate the actual temperatures achieved in the prostate during hyperthermia. Reliable temperature calculations during hyperthermia of prostate carcinoma are difficult to achieve. Thus, intra-prostatic temperatures in the cytotoxic range would be desiderable even in the context of thermoradiotherapy, where thermoablative temperatures may not be required, because optimal temperature homogeneity cannot be assumed with conventional heating methods.

Magnetically mediated interstitial hyperthermia has the potential to overcome the known limitations of conventional heating methods [19]. In these systems, heat can be delivered selectively to magnetic implants brought directly into the target volume. In contrast to the electric field in radiofrequency hyperthermia, interference of the AC magnetic field with healthy tissues is negligible. Furthermore, there are no limitations of efficacy due to reflection and absorption phenomena, which can be encountered in deep regional hyperthermia using microwave or ultrasound techniques [20]. Thermally self-regulating ferromagnetic seeds have been developed for hyperthermia and investigated by several groups [21, 22]. Deger et al. [2] conducted a phase II-study using cobalt-palladium-thermoseeds, which were permanently implanted into the prostate. An intermediate analysis of this trial was recently reported. Mean intra-prostatic temperature achieved in 57 patients was $44^{\circ} \mathrm{C}$ in this study. However, clinical effectiveness of this technique depends strongly on correct spacing of the seeds, since a distance of more than $1 \mathrm{~cm}$ between one seed and another may result in thermal under-dosage.

Thermotherapy with magnetic nanoparticles or magnetic fluid hyperthermia (MFH) represents a novel technique for inductive hyperthermia, which has several unique features. The small size as well as the large number and huge surface of heating elements 
within magnetic fluid suspensions result in very high power absorption in an AC magnetic field [4]. Thus, thermotherapy with magnetic nanoparticles has the potential to yield a higher intra-tumoural temperature homogeneity compared to much larger implants. A further characteristic of this method is intra-cellular uptake of the particles. Due to their aminosilan-type coating, the nanoparticles are taken up intra-cellularly by differential endocytosis [23]. Moreover, selective uptake into prostate cancer cells has been shown in vitro and offers the perspective of tumour-cell-selective hyperthermia [5].

In the first clinical application of hyperthermia using magnetic nanoparticles in prostate cancer, the aims to prove feasibility as a minimally invasive technique and to obtain thermoablative temperatures in the prostate were achieved. Importantly, the nanoparticles are retained in the prostate for at least 6 weeks following a single intra-tumoural application, allowing for repeated effective heat treatments. However, distribution of nanoparticles in the target region is still sub-optimal and must be improved. While TRUS-guided application of magnetic fluid into the prostate appears relatively easy and safe for the urologist experienced in prostate brachytherapy, direct visualization of nanoparticles by means of ultrasound is insufficient. Thus, TRUS allows the application of magnetic fluid depots, maintaining a certain safety margin towards sensible structures like rectum and urethra, but precise real-time evaluation of the distribution of nanoparticles and the margin of such a depot relative to the rectum or urethra is not possible. This is, however, possible immediately after application-and at later time points-using CT. Hence, CT-guided intra-prostatic application of magnetic fluid is a possibility and may offer the advantage of higher precision of the injection procedure, along with real-time assessment of nanoparticle distribution in the prostate. However, no equipment is presently available to support such an approach and the costs would be considerable.

Tissue alterations caused by previous treatments might also influence the precision of intra-prostatic application of magnetic fluid and its subsequent distribution in the prostate. It has been demonstrated that, following definitive radiotherapy, especially if partly or completely administered interstitially, metabolic atrophy and subsequent fibrotic changes take place in the prostate [24]. While this may render application of magnetic fluid more difficult and impair homogeneous distribution of nanoparticles, it may on the other hand inhibit rapid removal of nanoparticles by macrophages. Accordingly, it is not known if magnetic nanoparticles would be retained in non-irradiated prostatic tissue to the same extent as after high-dose radiotherapy. Although in the orthotopic prostate tumour model of the rat, intra-tumoural deposition of nanoparticles was sufficiently high and stable without previous irradiation and regardless of whether thermotherapy was carried out or not, these data cannot be extrapolated to the human prostate and this issue requires further investigation [7].

Finally, there is considerable potential regarding the applicable magnetic field strength, since only one third of the available power was used so far. If higher magnetic field strengths could be applied, much higher treatment temperatures might be obtained in the prostate, because SAR increases quadratically with the magnetic field strength [8]. This might also compensate for sub-optimal particle distribution to a certain extent. Efforts will be made in order to increase field strength while minimizing patient discomfort in future hyperthermia treatments of prostate cancer using magnetic nanoparticles.

\section{Conclusions}

Hyperthermia using magnetic nanoparticles was feasible and well tolerated in this pilot study in previously irradiated and locally recurrent prostate carcinoma. Maximum intra-prostatic 
temperatures achieved are in the thermoablative range. Interstitial deposition of nanoparticles in the pre-irradiated prostate is stable for several weeks, making sequential hyperthermia treatments possible without the need for repeated application of magnetic fluid into the prostate. Further refinement of the technique is necessary and will focus on optimization of intra-prostatic application and distribution of nanoparticles as well as temperature calculations. In the future, this treatment modality may be combined with interstitial or external irradiation in patients with localized prostate cancer, should the results of a recently initiated phase I study confirm the preliminary experiences regarding feasibility and toxicity.

\section{Acknowledgements}

This study was supported by the EFRE project 'NanoMed', Nanotechnology in Medicine, No. 20002206 2UE/2, and the Federal Ministry for Education and Research (BMBF, Nanobiotechnology Program, project 'TAN', FKZ 13N8679). The authors thank Eva Wasserberg, Cornelia Cordes, Sabine Müller, Young-Suk Frisch and Dipl. Ing. V. Brüß for valuable technical assistence.

\section{Disclosure statement}

Andreas Jordan is a manager and Uwe Gneveckow, Regina Scholz and Norbert Waldöfner are employees at MagForce ${ }^{\circledR}$ Nanotechnologies $\mathrm{GmbH}$, Berlin, Germany. The other authors declare that they do not have any affiliations that would lead to conflict of interest.

\section{References}

1. Deger S, Boehmer D, Turk I, Roigas J, Wernecke KD, Wiegel T, Hinkelbein W, Dinges S, Budach V, Loening SA. High dose rate brachytherapy of localized prostate cancer. European Urology 2002;41:420-426.

2. Deger S, Taymoorian K, Boehmer D, Schink T, Roigas J, Wille AH, Budach V, Wernecke KD, Loening SA. Thermoradiotherapy using self-regulating thermoseeds: An intermediate analysis of a phase II trial. European Urology 2004;42:574-580.

3. Tilly W, Gellermann J, Graf R, Hildebrandt B, Weißbach L, Budach V, Felix R, Wust P. Regional hyperthermia in conjunction with definitive radiotherapy against recurrent or locally advanced prostate cancer T3 pN0 M0. Strahlentherapie und Onkologie 2005;1:35-41.

4. Jordan A, Wust P, Fähling H, John W, Hinz A, Felix R. Inductive heating of ferrimagnetic particles and magnetic fluids: Physical evaluation of their potential for hyperthermia. International Journal of Hyperthermia 1993;9:51-68.

5. Jordan A, Scholz R, Maier-Hauff K, Johannsen M, Wust P, Nadobny J, Schirra H, Schmidt H, Deger S, Loening SA, Lanksch W, Felix R. Presentation of a new magnetic field therapy system for the treatment of human solid tumors with magnetic fluid hyperthermia. Journal of Magnetics and Magnetic Materials 2001;225:118-126.

6. Johannsen M, Jordan A, Scholz R, Lein M, Koch M, Deger S, Roigas J, Jung K, Loening SA. Evaluation of magnetic fluid hyperthermia in a standard rat model of prostate cancer. Journal of Endourology 2004;18:495-500.

7. Johannsen M, Thiesen B, Jordan A, Taymoorian K, Gneveckow U, Waldöfner N, Scholz R, Koch M, Lein M, Jung K, Loening SA. Magnetic fluid hyperthermia (MFH) reduces prostate cancer growth in the orthotopic Dunning R3327 rat model. Prostate 2005; Feb 22 [Epub ahead of print].

8. Gneveckow U, Jordan A, Scholz R, Bruss V, Waldofner N, Ricke J, Feussner A, Hildebrandt B, Rau B, Wust P. Description and characterization of the novel hyperthermia- and thermoablation-system $\mathrm{MFH} 300 \mathrm{~F}$ for clinical magnetic fluid hyperthermia. Medical Physics 2004;31:1444-1451. 
9. Sreenivasa G, Gellermann J, Rau B, Nadobny J, Schlag P, Deuflhard P, Felix R, Wust P. Clinical use of the hyperthermia treatment planning system hyperplan to predict effectiveness and toxicity. International Journal of Radiation Oncology, Biology \& Physics 2003;55:407-419.

10. Anscher MS, Samulski TV, Dodge R, Prosnitz LR, Dewhirst MW. Combined external beam irradiation and external regional hyperthermia for locally advanced adenocarcinoma of the prostate. International Journal of Radiation Oncology, Biology \& Physics 1997;37:1059-1065.

11. Algan Ö, Fosmire H, Hynynen K, Dalkin B, Cui H, Drach G, Stea B, Cassady JR. External beam radiotherapy and hyperthermia in the treatment of patients with locally advanced prostate carcinoma. Cancer 2000;89:399-403.

12. VanVulpen M, De Leeuw AAC, Raaymakers BW, Van Moorselaar RJ, Hofman P, Lagendijk JJ, Battermann JJ. Radiotherapy and hyperthermia in the treatment of patients with locally advanced prostate cancer: Preliminary results. BJU International 2004;93:36-41.

13. Kalapurakal JA, Pierce M, Chen A, Sathiaseelan V. Efficacy of irradiation and external hyperthermia in locally advanced, hormone-refractory or radiation recurrent prostate cancer: A preliminary report. International Journal of Radiation Oncology, Biology \& Physics 2003;57:654-664.

14. Hurwitz MD, Kaplan ID, Hansen JL, Prokopios-Davos S, Topulos GP, Wishnow K, Manola J, Bornstein BA, Hynynen K. Association of rectal toxicity with thermal dose parameters in treatment of locally advanced prostate cancer with radiation and hyperthermia. International Journal of Radiation Oncology, Biology \& Physics 2002;53:913-918.

15. Fosmire H, Hynynen K, Drach GW, Stea B, Swift P, Cassady JR. Feasibility and toxicity of transrectal ultrasound hyperthermia in the treatment of locally advanced adenocarcinoma of the prostate. International Journal of Radiation Oncology, Biology \& Physics 1993;26:253-259.

16. Petrovich Z, Emami B, Kapp D, Sapozink MD, Langholz B, Oleson J, Lieskovsky G, Astrahan M. Regional hyperthermia in patients with recurrent genitourinary cancer. American Journal of Clinical Oncology 1991;14:472-477.

17. VanVulpen M, De Leeuw AAC, Van de Kamer JB, Kroeze H, Boon TA, Warlam-Rodenhuis CC, Lagendijk JJ, Battermann JJ. Comparison of intra-luminal versus intratumoural temperature measurements in patients with locally advanced prostate cancer treated with the coaxial TEM system: Report of a feasibility study. International Journal of Hyperthermia 2003;19:481-497.

18. Tilly W, Wust P, Rau B, Harder C, Gellermann J, Schlag P, Budach V, Felix R. Temperature data and specific absorption rates in pelvic tumours: predictive factors and correlations. International Journal of Hyperthermia 2001;17:172-188.

19. Moroz P, Jones SK, Gray BN. Magnetically mediated hyperthermia: Current status and future directions. International Journal of Hyperthermia 2002;18:267-284.

20. Coughlin CT. Interstitial thermobrachytherapy. In: S. Nag, editor. Principles and practice of brachytherapy. New York: Futura publishing; 1997. pp 639-647.

21. Burton AL, Hill M, Walker AE. The RF thermoseed - a thermally self-regulating implant for the production of brain lesions. IEEE Transactions on Biomedical Engineering 1971;18:104.

22. Paulus JA, Richardson JS, Tucker RD, Loening SA, Park JB. Evaluation of inductively heated ferromagnetic alloy implants for therapeutic interstitial hyperthermia. IEEE Transactions on Biomedical Engineering 1996;43:406-413.

23. Jordan A, Scholz R, Wust P, Schirra H, Schiestel T, Schmidt H, Felix R. Differential endocytosis of dextran and silan-coated magnetite nanoparticles and the effect of intracellular hyperthermia on human mammary carcinoma cells in vitro. Journal of Magnetics \& Magnetic Materials 1999;194:185-196.

24. Pickett B, Ten Haken RK, Kurhanewicz J, Qayyum A, Shinohara K, Fein B, Roach M 3rd. Time to metabolic atrophy after permanent prostate seed implantation based on magnetic resonance spectroscopic imaging. International Journal of Radiation Oncology, Biology \& Physics 2004;59:665-673. 